\title{
Study of the Uniformity of the Coating Thickness of Pellets Coated by Wurster and Swirl Flow Generator Equipped Coater
}

\author{
M. LUŠTRIK $^{1,2}$, R. DREU ${ }^{1}$, S. SRČIČ ${ }^{1}$ \\ ${ }^{1}$ Faculty of Pharmacy, University of Ljubjlana, Ljubljana, Slovenia \\ ${ }^{2}$ Brinox d.o.o., Sora 21, 1215 Mevode, Slovenia \\ E-mail: matevz.lustrik@ffa.uni-lj.si (M. Luštrik)
}

Sci Pharm. 2010; 78: 641

doi:10.3797/scipharm.cespt.8.PMS14

The problem emerging from particle coating is how to manufacture particles with just enough material deposited to achive the desired result [1]. Especially in case of functional coatings, the uniformity of coating thickness over the entire particle surface plays an important role. In our study the performance of two bottom spray coaters and the effect of the particle motion on the coating uniformity were evaluated for the pellets with wide size distribution. In the first case the traditional Wurster coater was employed, while in the second one the coater with a swirl flow generator was used. Pellets (Cellets ${ }^{\circledR}$, Syntapharm, Germany) of four different sieved fractions (300-400, 500-600, 700-800 and 900-1000 $\mu \mathrm{m}$ ) were used in each coating experiment. Fractions of pellets comprising the bed were separated after dye dispersion coating, using the same sieves as used in the preparation of starting cores. Spectrofotometric evaluation of the dye concentration on the population of pellets from each fraction of every experiment was done. Results confirmed the fact that pellets having smaller diameter receive significantly less coating material compared to the larger ones when using conventional bottom spray coater with Wurster insert [2]. The ratio of mass of coating deposited on the pellet to the pellet surface indicates the coating thickness to be much more evenly distributed over the pellets coated with the use of swirl flow generator equipped coating chamber. For example the values of dye per particle surface varied from 0.88 for smallest fraction to $2.12 \mu \mathrm{g} / \mathrm{mm}^{2}$ for largest fraction in case of conventional Wurster coating chamber and only from 1.21 to $1.79 \mu \mathrm{g} / \mathrm{mm}^{2}$ in case of application of swirling airflow generator. These results also indicate that the amount of dye deposited per particle is in a strong correlation with the particle diameter to the power of 2.36 in case of coater with swirl airfow, compared to the value of 2.85 obtained by a conventional bottom spray coater. The amount of dye per pellet would ideally be in correlation with pellet surface $\left(d^{2,00}\right)$, which makes swirl flow coater more suitable for coating particles with wide size distribution. The improvement in the yield of the process was also observed in the case of swirling airflow coater.

[1] Chan L, Tang ES, Heng PW. Comparative study of the fluid dynamics of bottom spray fluid bed coaters. AAPS PharmSciTech. 2006; 7: E37. doi:10.1208/pt070237

[2] Sudsakorn K, Turton R. Nonuniformity of particle coating on a size distribution of particles in a fluidized bed coater. Powder Technol. 2000; 110: 37-43. doi:10.1016/S0032-5910(99)00266-1 